\title{
Transcription Factor SOX-2
}

National Cancer Institute

\section{Source}

National Cancer Institute. Transcription Factor SOX-2. NCI Thesaurus. Code C61139.

Transcription factor SOX-2 protein (317 aa, 34 kDa) is encoded by the human SOX2 gene. This protein is involved in neural cell progenitor differentiation and neurogenesis. 